INTERNATIONAL DESIGN CONFERENCE - DESIGN 2018

https://doi.org/10.21278/idc.2018.0334

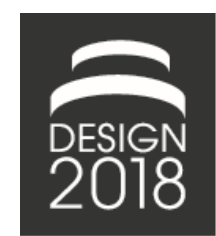

\title{
WHEN LIFECYCLE COST ANALYSIS ENABLES STRATEGIC DESIGN CONSIDERATIONS
}

\author{
S. Altavilla and F. Montagna
}

\begin{abstract}
The literature on cost-estimation is full of examples that methodologically explain the construction of models. In this paper, we showed how such methods when correctly implemented represent a source of structured information for in-depth design decisions. We investigated the impact of variety proliferation overall lifecycle costs, assessing differences in product architectures using a cluster analysis. The evidence collected serves as validation of a cost model approach and provides a decision-making support for choosing between platform solutions against a knowledge of costs consequences.
\end{abstract}

Keywords: design for $x(D f X)$, design costing, platform strategies, early design phase

\section{Introduction}

Nowadays, the industrial digital transformation imposes new challenges and opportunities to all manufacturing contexts (Holzhauser and Schalla, 2017). The consistent collection of an enormous amount of data coming from the increasing intelligence of manufacturing plants is, in fact, enabling different decision-making paths within the entire process of developing, producing and maintaining products and services (Rimmy and Sharma, 2016).

As the entire manufacturing environment is changing, methods and approaches thought for supporting companies during product development processes are changing too. In this context, also the activity of cost analysis has been affected by this big-data revolution. In fact, although product cost estimation (PCE) has been widely discussed in the literature for more than twenty years, new advanced data-driven methodologies, coming from other fields as data mining and software engineering, have been lately implemented for cost analysis (Altavilla et al., 2018). This mainly because, the vast amount of real-time data opens to new typologies of possible applicable techniques and methodologies, as well as they multifold foster the number of potential applications, allowing more in-depth cost considerations (Choudhary et al., 2009).

Traditionally, a cost analysis has been employed to evaluate concept feasibility and to constrain design decisions, so to derive the best solution at minimum costs. In particular, during the early design phases when the product concept is not defined yet, and the possibility of influencing costs is higher than in other phases (Dowlatshahi, 1992). This is mainly due to the way designers usually approach product development, which is technology oriented, while economic or operational issues are typically overshadowed (Cavalieri et al., 2004).

Cost considerations can be differently implemented during the development process as a driver for exploring product architectures, evaluating several design alternatives and for enhancing platform decisions (Asiedu et al., 1998; Park and Simpson, 2008). Even more when the input information for the cost analysis regards not only the usual production phase (e.g. number of assembling stages), but also data from development (e.g. number of product variants, product tree, development effort), operations 
(maintenance programs, logistic flows, etc.) and end-of-life phases (disassembling stages, recycling policy, energy consumption etc.).

For instance, driving the concept design by a cost analysis can avoid designers to take saving choices at the early development phase (on a component, part or material), which can have expensive consequences later at the end of a product lifecycle. It can allow decisions on the degree of a platform standardisation, on the breadth and depth of product lines to be developed, as well as on the degree of variety to be offered. For example, in designing product families, estimating cost savings becomes an emerging challenge for developing cost-effective products. At this time, customers' needs in various market segments are translated into the individual products in the family, and standard components or subsystems of the products are combined as a product platform that supports the products (Simpson, 2004). Increasing than the degree of standardisation in the product family decreases costs related to the product design and development, as well as all the indirect cost, addressed to inventory, setup, inspection, maintenance, material handling and storage. Instead, the spreading of product variants, as well as the uncontrolled planning of differentiated products on the market, can reduce the overall benefit of platform strategies.

Considering these aspects might represent a strategic way of conducting a cost analysis, which beyond the estimated economic return, enables better evaluation of the impact of product configuration and platform decisions on the entire lifecycle.

Nevertheless, despite the recognised importance of product cost analysis, and the new opportunities provided by a more reliable and in-depth cost estimation, the adoption of such methods appears limited in the industry yet (Layer et al., 2002; Newnes et al., 2008). This perhaps because the need for a systematic and comprehensive data collection in organisations (Ma et al., 2014), and the way the generated knowledge is integrated and re-used in development processes (Hicks et al., 2002) remain always discussed, but unsolved matters. There is still a considerable confusion on the kind of technique directly applicable for the specific problem to solve or about how efficiently exploit the benefit of a cost analysis (Altavilla et al., 2018).

Therefore, this paper addresses all these challenges, and starting from the implementation of a lifecycle cost methodology, describes the possible strategic analysis that can be derived. Indeed, the focus is usually on how to collect data and build a cost estimation model. In this study, we reverse the perspective by showing how such methods, if correctly implemented, can represent a source of structured information valuable for strategic decisions.

To this purpose, this paper starts from the output of a cost estimation methodology, previously presented in (Altavilla and Montagna, 2015). On this data, here, a cluster analysis on different platform alternatives is built. By examining the possible mix of component standardisations, the object of this paper is to evaluate the optimal number of product variants and the performances of platform structures to provide more conscious planning of the product portfolio.

The paper is structured in four sections. Section 2 reviews the lifecycle cost methodologies and focuses on the economic evaluation of platform strategies. Section 3, methodologically starts from the data structure derived from the cost estimation methodology presented in (Altavilla and Montagna, 2015) and sets the framework for the following analysis. The approach is then applied and validated to an industrial case in Section 4.

\section{Review of the lifecycle cost methods}

A conventional representation of PCE states the approaches hierarchically divided between Qualitative and Quantitative (Niazi et al., 2006). The former category of models derives the cost estimation from a comparison of the new concept with previous similar cases (Seo and Ahn, 2006; Duran et al., 2009). The latter provides a more in-depth decomposition of new product at the component/process level so to build-up the cost approximation (Cavalieri et al., 2004; Cheung et al., 2015). Obviously, choosing one method instead of another is deeply influenced by the stage of the development process (Rush and Roy, 2000), as well as by the type and amount of data available (Niazi et al., 2006; Altavilla et al., 2018). In general, Qualitative Approaches are more appropriate at the conceptual design stage (Layer et al., 2002; Niazi et al., 2006), using historical data (Seo, 2006) or structure/unstructured experts knowledge (H'mida et al., 2006; Zhao et al., 2015). Quantitative methods instead employ more accurate product and process information, generally available at the detail design stage (Kaufmann et al., 2008; Johnson 
and Kirchain, 2009; Haroun, 2015). Indeed, a general trend in combining different techniques results in the literature (Altavilla et al., 2018), since integrated models try to overcome the drawbacks within each single cost estimation technique, consequently enabling anticipated cost assessments (Lin et al., 2011). The most recent interests in developing digital and dynamic cost modelling also represent another trend. The attention of the estimators, in fact, is focusing not only on the quality and accuracy of the cost analysis but also on the ways available data can be filtered and used as input for more dynamic cost estimation methods (Deng and Yeh, 2011; Sajadfar and Ma, 2015).

Methods and techniques for product cost estimations have been developed traditionally for specific and very detailed applications (Asiedu, 1998; Layer et al., 2002; Altavilla et al., 2018). Usually, the aim has been to generate design alternatives (Brunoe and Nielsen, 2012; Fazlollahtabar and Mahdavi-Amiri, 2013; Waghmodel, 2014), or to evaluate and select different design options, by narrowing down the selection to some possible choices (Lee et al., 2011; Helbig et al., 2014; Loyer and Henriques, 2014). When the decision between design solutions is performed at the early design phases, mainly the cost evaluation is made on functional requirements (Brunoe and Nielsen, 2012), product performances (Saravi et al., 2008; Fazlollahtabar and Mahdavi-Amiri, 2013) or physical characteristics (Kaufmann et al., 2008).

Still, the implications derived from the cost analysis were limited to the most regular evaluation of different cost profiles. In very few cases, the alternatives were compared to the entire product lifecycle (Liu et al., 2008; Hongzhuan et al., 2013). Once the estimation was obtained, cost monitoring and control activities were also usually performed (Lindholm and Suomala, 2007). In fact, the approximation can be mainly substituted with the actual cost values, obtaining then a more reliable evaluation.

However, at the end of cost analysis, the data collected and analysed and the knowledge gained can enable further relevant operative and strategic consequences (Altavilla et al., 2018). Even more when the estimation is implemented at the beginning of the product development phase. In fact, at this stage, having already a detailed breakdown of costs, besides in-depth knowledge of a product lifecycle processes, can be helpful for designers for better understanding the impact of their decisions on the overall performance of a product. In particular, whether investigations on the relevance of product standardisation and the role of different product variants (as consequences of the broadness of product line) are taken into account.

\subsection{Can PCE support the study of platform advantages?}

Coping with the effect of product variety and the quest for approaches to managing the economic impact of platform strategies have been the focus of a wide stream of literature, for years. Different models have been created to determine the optimal width of product families, considering the incurred production costs in handling a broader product line, as well as the trade-offs deriving from different resource-sharing choices (Krishnan et al., 1999). Numerous studies looked more in general at the advantages and disadvantages of a platform design approach, as well as on the profitability of a more extensive product line (Meyer and Utterback, 1993). Moreover, the impact of product variety on manufacturing operations has been the object of several empirical evaluations. For instance, Kekre and Srinivasan (1990) focused on the direct and indirect effects of product line breadth, by measuring the influence of the variety proliferation on marketing performance and manufacturing costs.

By looking more specifically at cost implications, it has been proven that a broader product line leads to higher direct labour and material costs. More in general, it results in a sharp rise of manufacturing overhead expenses, mainly due to low volumes, higher product complexity higher material handling and inventories expanses, higher quality and level of defect supervision (Foster and Gupta, 1990). However, the majority of studies focuses on the effect of platform strategies and variety proliferation against the production and manufacturing phase, few cases apart (Lin et al., 2007). Even the models that adopt a lifecycle perspective are then implemented later in the product development process, or even when the product is already in the production and phase since they require data not available during design.

Hence, very few examples are available on the effects of lifecycle methodologies in an organisation. In particular, on how to exploit the cost analysis, which if applied to the whole lifecycle, provides a tide of information in support of platform strategy. In filling this gap in the literature, this paper starts from the data structured by an implemented cost methodology at the conceptual design phase and develops specific empirical evaluation on the impact of product variety and platform decision making in the entire product lifecycle. 


\section{Implications derived from a lifecycle methodology: From cost estimation to platform decisions}

This paper develops on the output of the methodology introduced in Altavilla and Montagna (2015). The lifecycle cost methodology, integrates qualitative and quantitative techniques, such as Case-BaseReasoning (CBR), Activity-Based Costing (ABC) and Parametrical Cost Estimation Relationship (CER). The integration of these techniques, from a methodological point of view, requires moving between different data granularity levels. This is because typically these approaches have been employed at different moments of the product development process, when also the designers move from a general concept (product level), then goes down deep to the details (component level), to finally derive the entire design (product level again). Hence, the proposed methodology changes the reference system following dynamically the same flow of information and activities of a product development process.

In particular, usually, the CBR technique is used to recover from a database, past product designs that have the highest similarities with the new concept. The case-based memory is organised in a hierarchical structure, following the same structure of a Bill-of-material (BOM). Different product levels are hierarchically represented, and each successive step corresponds to a different level of product design, up to the single component. The integration with a quantitative technique (ABC) occurs when also information on the lifecycle is included. Moreover, when an entirely new product is designed, and there are no previous cases available in the database for it, the $\mathrm{ABC}$ can still be an adequate bottom-up approach, although onerous, for cost estimation, which can be immediately implemented at the early design phases. The parametrical analysis, instead, is used to identify, at each level, the cost drivers.

The proposed approach is consequently organised in three steps, as depicted in Figure 1. In Step 1, the information obtained relates to the product level, and costs have been calculated both on the product and the process. In Step 2 the methodology goes down to a single component, and here again, process and product costs are derived. All the data collected are then implemented as cost drivers to be used in the parametrical equation. Finally, in Step 3, the approach aggregates information back to the product level, through a parametric evaluation, to calculate the overall lifecycle cost of the product.

At the end of the three steps, the output obtained is first an early evaluation of costs, which can be immediately implemented at the conceptual design phase. However, what is more important and also represents the novelty of the approach, is the structure that results from the data collected and analysed.

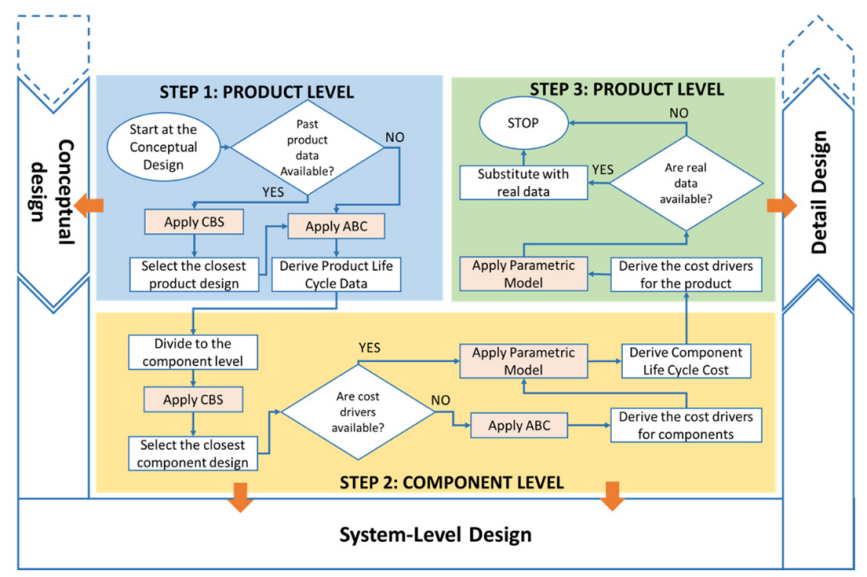

Figure 1. The flow chart of the integrated approach for lifecycle cost analysis

In fact, structuring the information at the different levels of the product tree provides a symmetrical framework to the lifecycle knowledge, which can be successively implemented in more in-depth operative and strategic analysis. Figure 2 lists some instances of knowledge elements that are derived. At the component level, data concern the shape, geometry, tolerances together with the volume and weight of each part. Moreover, economic data on material costs, resources consumption, but also strategic make or buy decisions are provided for each single lifecycle activity. At the assembly aggregation level, the process aspect is also fundamental, since that at this time, the highest consumption of resources regarding product manufacturing happens. At this point, a better view of the possible 
operative costs is available. Finally, at the product level, the information extracted and made available is usually related to the type of product, the product segment, and its performance and production volume. The abstraction at this point is such that a general view of the platform strategy is available, including the possible product versions in a single family, and the degree of the offered variety.

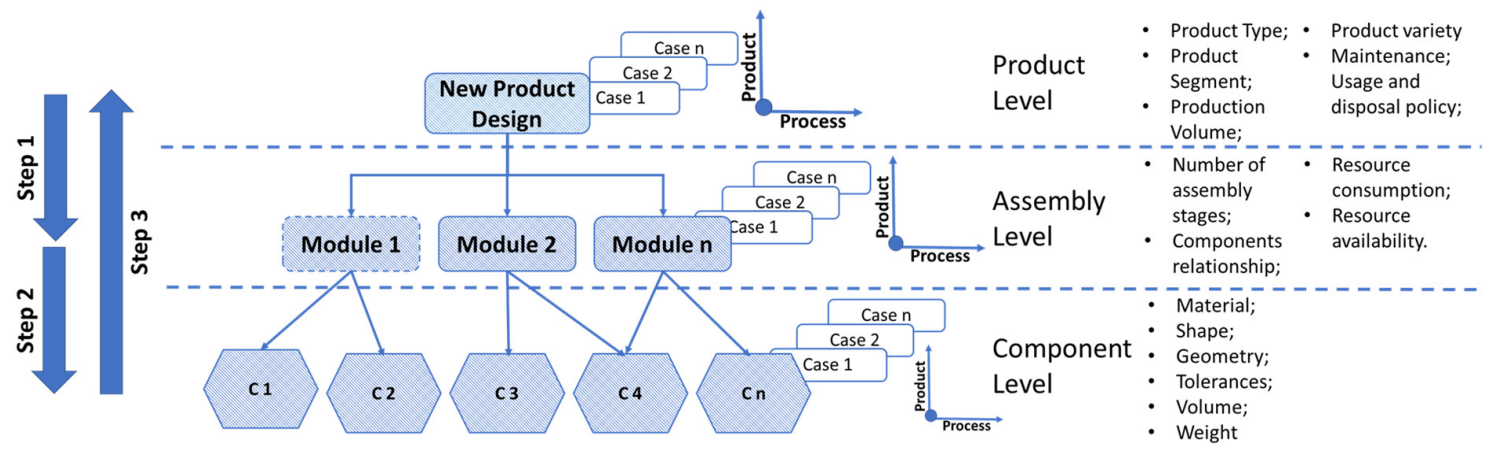

Figure 2. The data framework related to the different aggregation level of the product tree

Therefore, once the data are presented at these varying degrees of granularity respect to the product tree, various are the advantages for further investigations. For instance, if the object is on the choice between different production processes of a single component, maybe the bottom level of the data framework can be investigated. On the contrary, if the concern is on the degree of differentiation of a product line on the market, data coming from the product and assembly aggregation level are better suited.

In this paper, starting from the obtained data framework, we propose an investigation on the impact of product standardisation, as well as the proliferation of products variants on the whole lifecycle costs. Accordingly, the purpose of this study is to examine variations in the architecture of a family of products, by starting form differences in product lifecycle costs. Do past design decisions explain these differences in any way at a platform level? Is it possible to provide designers with a better predictive tool for measuring the impact of variety proliferation?

Answers can be obtained, by querying the data framework at a specific product aggregation level, clustering concepts in term of variations. However, historical data are employed (coming from the use of the CBR), at the beginning. Once the development of the new product is advanced, those data can be replaced with the actual information and integrated with the one provided by the quantitative techniques. This allows measuring valuable differences in lifecycle costs between and within the groups and deriving managerial implications since the beginning of product design. Hence, analyses that usually have been performed later in the product development process (or even during production) can be moved up at the early design phases, thanks to different techniques integration.

\section{The application case}

The presented methodology was implemented and validated at an automotive company that designs, produces, and commercialises measurement devices for engine development.

Among the company's units, the segment of combustion measurement systems was chosen for empirical investigations. The portfolio contains different product families, ranging from data acquisition devices, amplifiers and angle calculators, to sensors and cables. However, the company was planning an upgrade of the data acquisition devices (DAD) family, on which the methodology was tested.

Three line of devices are for data analysis, as shown in Figure 3, and the differences among them are mainly due to the set of different product specifications and to the type of applications. Moreover, they are thought for different market segments. For instance, the low-end product line, the $\mathrm{xxx} 322$, was developed for non-complex and first-time-user applications. The medium and high-end lines are instead suitable for light/heavy-duty, racing, and large engines development and calibration. Consequently, the differences among the derived six product versions are due to the number of input-analogue channels (ranging from a minimum of 4 up to 64 channels), the speed of the analysis, and the compliance with a more complex version of the post-processing software. 


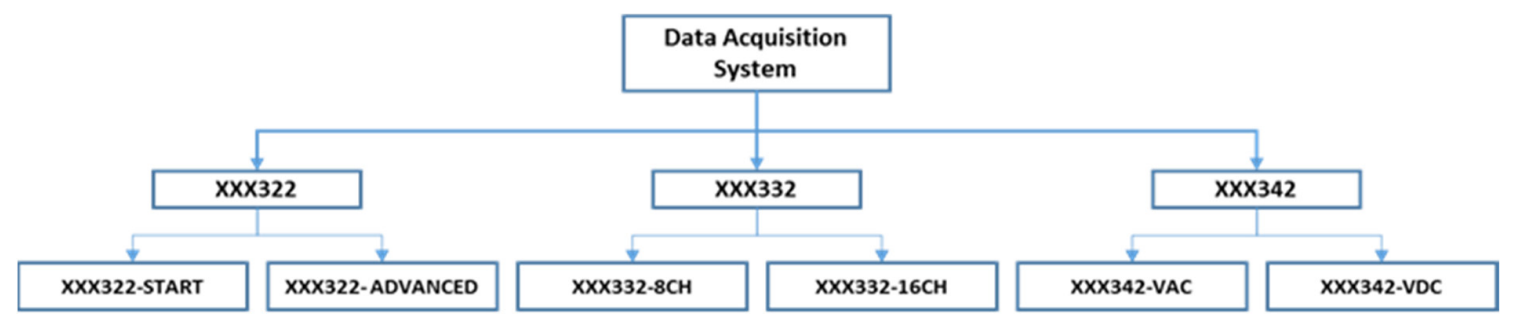

Figure 3. Product family of data acquisition devices

On the main business processes, an analysis to identify the main lifecycle phases and the source of data from which gather the necessary information was performed. Accordingly, data were collected from each department involved in the lifecycle process, going from Research and Development to the Operation and Support Phase. Data were therefore cleaned, integrated and organised by product and lifecycle phases on a central dataset.

\subsection{The lifecycle cost approach application}

According to the integrated cost methodology, the existent DAD family was first queried from the casebased memory, in Step1. In Step 2, the structure of each product version was divided up to the single component level (around 80 components for a single product version). The $\mathrm{ABC}$ was performed at the component level to identify the main activities for each lifecycle phase. These data for all the components were used for deriving the total cost of ownership for the new product to develop.

At the end of these first two preliminary steps, information on the product, divided by aggregation level was derived. In fact, geometrical and structural information for each part was obtained at the component level. On the product level, already data on the BOM structure, together with the possible sales volume were identified. Finally, from the entire product family, information on the likely number of versions, options, and degree of standardisation was derived. All this data represented possible cost drivers to be used in the construction of the parametrical CER. A one-to-one regression analysis was performed to identify the likely set of variables, reaching a total number of 19 possible candidates. In Step 3, a stepwise regression procedure was then applied, and the unnecessary parameters, which did not fit into the model, were dropped based on their p-value and collinearity with each other. All the regression analysis were performed by using the IBM SPSS statistical software, version 18.0.

The best set of activity drivers was eventually recognised for each lifecycle phase, as described in Table 1. In Table 2 the resulting parametric models with the derived regression coefficients are reported, divided by different lifecycle phase. To validate these two models, previously separated data were used, resulting in an average absolute error of around 5.34\%. Once the actual data are available on the new product, the predicted value can be consequently replaced.

Table 1. Activity drivers and their definitions

\begin{tabular}{lll} 
Activity Driver Name & \multicolumn{1}{c}{ Description } \\
\hline Duration (h) & X1 & It is the amount of projects' hours assigned to a single product. \\
\hline Quantity (pc.) & X2 & It expresses the number of units of product sold in a single order. \\
\hline $\begin{array}{l}\text { Number of SW/HW } \\
\text { Options (pc.) }\end{array}$ & $\begin{array}{l}\text { X3/ } \\
\text { X4 }\end{array}$ & The number of Software/Hardware option sold in a single order. \\
\hline $\begin{array}{l}\text { Number of Parts (pc.) } \\
\text { X5 }\end{array}$ & It expresses the average number of parts between product variants. \\
\hline Number of Boards (pc) & X6 & It represents the number of the boards as a proxy of product modularization. \\
\hline $\begin{array}{l}\text { Number of Product } \\
\text { Version (pc.) }\end{array}$ & X7 & $\begin{array}{l}\text { The variable accounts for the different number of product versions available for } \\
\text { the product family. }\end{array}$ \\
\hline Finished goods [€/unit] & X8 & It accounts all the material costs related only to the instrument. \\
\hline Machine Hours [€/unit] & X9 & The voice expresses the costs of the production testing activity. \\
\hline $\begin{array}{l}\text { Machine Overhead } \\
\text { [€/unit] }\end{array}$ & X10 & $\begin{array}{l}\text { The variable accounts for all the material and production overhead in the } \\
\text { production of a single instrument. }\end{array}$ \\
\hline
\end{tabular}


Table 2. Linear parametric models

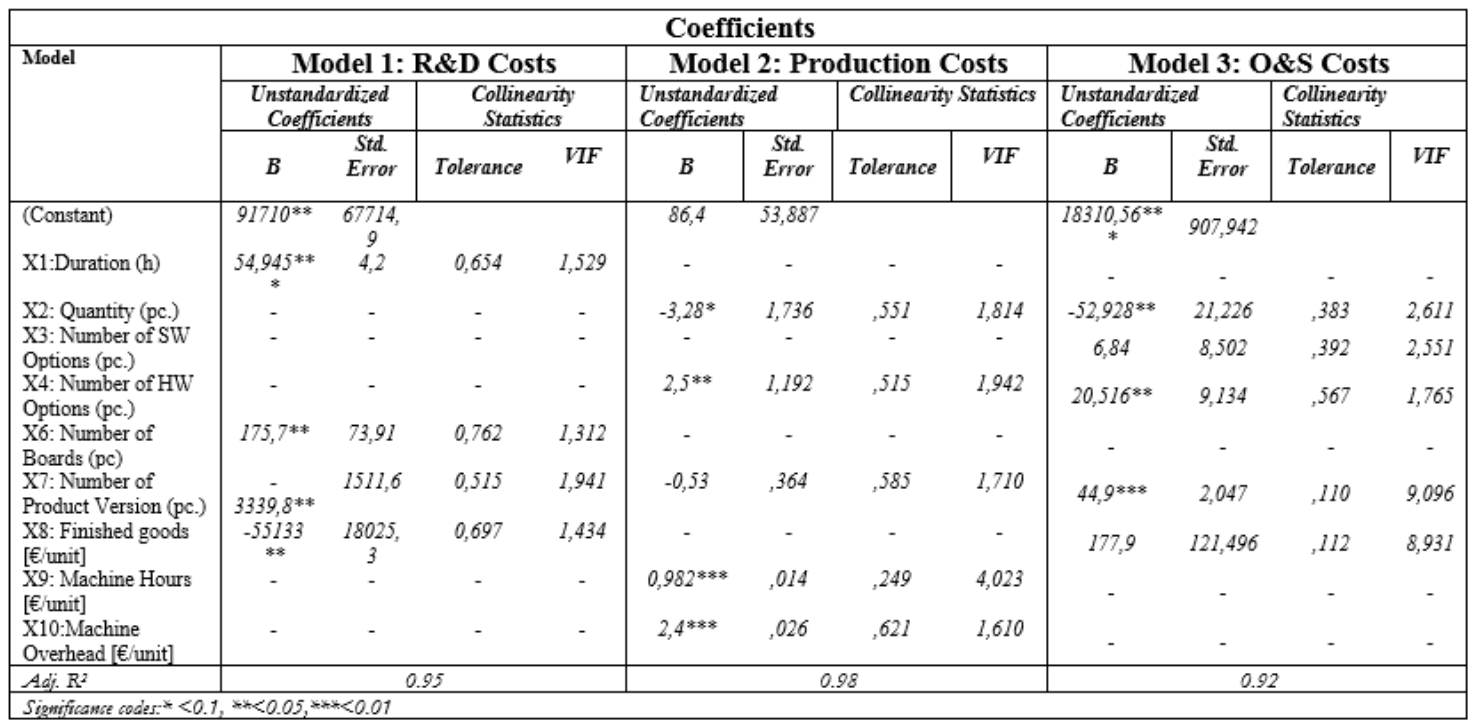

Considering that each data acquisition device is designed for a maximum of 10 years' life, the total cost of ownership of the new product, reduced to its present equivalent value, can be derived. This pattern is shown in Figure 4 and can be used eventually either to evaluate the impact of different design alternatives (but still using past data as input) or to assess how the various functional choices create different trends in the overall costs, especially in consideration of the extra maintenance activities sustained by the customer.

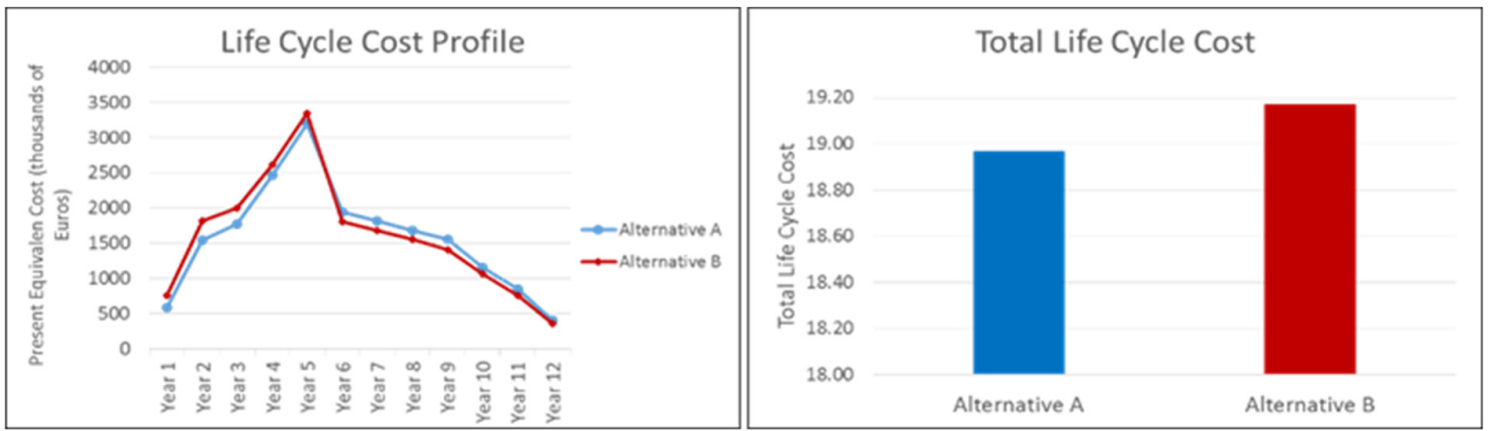

Figure 4. Lifecycle cost profile (a), and comparison of design alternatives (b)

Nevertheless, the object of our investigation goes beyond the usual cost analysis. In fact, each product can be manufactured as standardise equipment, or several hardware and software options can be added to the basic product configuration, reflecting than on a different customisation level.

In the specific case of the DAD family, the platform evaluated was characterised by 150 possible product variants. In particular, referring to Figure 2, for each product line, 50 possible mixes of options were available to customers.

Figure 5, as an example, plots the predicted cost values of each personalised architecture, for the low-

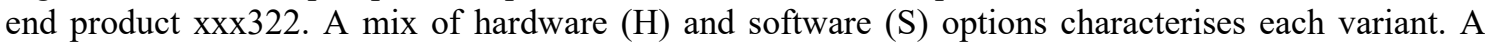
minimum can be reached when the product is assembled mainly with software options. Hence, the increase in costs among the values is primarily due to the rise in the number of out of platform hardware options that have been added to the standard product configuration, as well as an increase in their level of customisation. 


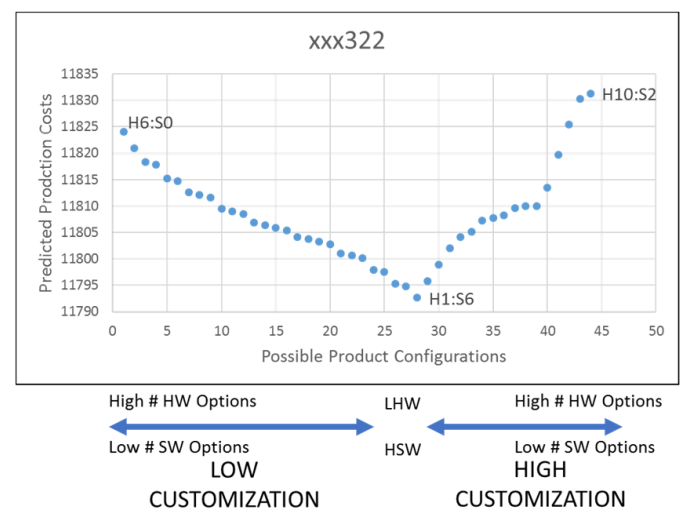

Figure 5. The predicted costs of the possible variants on the low-end product

Figure 6 compares the graph for each product line in the DAD family. It results evident that not only the level of customisation (high/low) and the kind of option (hardware/software) impact on the total production costs but also the product segment (low/medium and high-end) plays a role in costs differences. In particular, for medium and high-end products, the range of variants decreases, and respectively around 30 and 20 personalisations have been realised (on the 50 available). This can be justified by the set of functions provided by these products: as standardised instruments, they are already enough equipped and do not need any further customisation.

Moreover, the production costs reached a minimum value when the product is standardised. This reflects a typical problem of the adverse effect of platform design in cases of multiproduct families (Krishnan and Gupta, 2001), i.e. companies usually tend to exploit excessively the benefit of a platform, by increasing variety in a product family, without paying attention to the costs. Indeed, when a high complexity characterises the product, the distinction between market segments does not justify this excessive proliferation of variants.
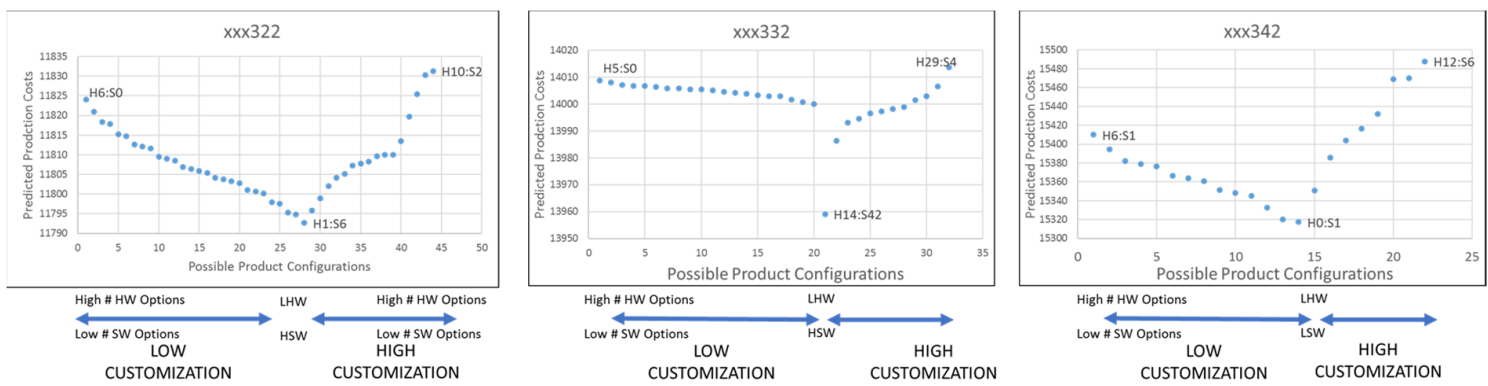

Figure 6. The predicted costs of the possible variants on the entire product family

The evidence of these results represents the validation of the lifecycle cost model. The model, in fact, behaves according to the expected results discussed in the managerial literature. Hence, its validity it is confirmed, and it can be consequently employed as a supporting tool for decision-making at the conceptual design phase. Therefore, designers can choose between different solutions against a precise knowledge of costs consequences.

To further investigate this effect, the K-means cluster analysis can be applied to all the product configurations. In this case, we looked at the composition of a customer orders over a five-year period (from to 2010 to 2015). In particular, for the $\mathrm{xxx322}$ product line, the dataset contained 284 records, together with all the options available for the customisation. The data were analysed using Ward's method with the squared Euclidean distance measure in SPSS 18.0. A first hierarchical clustering model was used to generate a dendrogram, which graphically illustrated how the architecture quickly grouped into four main clusters. Then, three iterations of the K-means cluster analysis were then performed, with a number of clusters set at three, four, and five, to check the stability of membership in the four groups. Anova was then used to prove differences among the four clusters. The F-statistic indicate strong evidence that the cluster means differed from another for all the defining variable at the 0,05 level of significance or less. 
The four clusters resulted in four different type of customised architecture showed in Figure 7. The first group joins all the standard product variants. It represents the most significant group with $88 \%$ of the cases in four clusters. The second group is similar to the first regarding the degree of standardisation but is characterised by a higher quantity required for a single customer order. The third cluster regards customised architectures, in particular with software options. Similarly, the fourth one is highly personalised, but in this case, hardware options are added to the basic architecture. Moreover, as for the second group, also, in this case, the quantity order is higher.

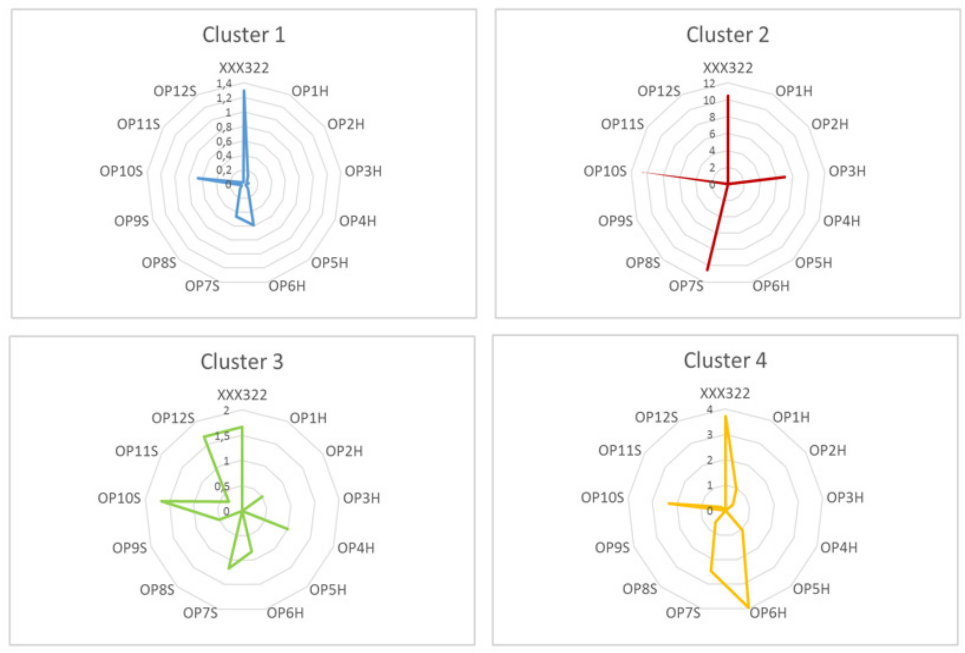

Figure 7. The four customised architectures

These observations were then validated statistically using a one-way Anova, using the four clusters as classes for the analysis. In Figure 8, the differences in the mean of the four groups are depicted, divided for each variable. It is immediately visible how the customisation, in general, affects the production costs negatively. In particular, this is visible in the differences between the clusters one and three. Hence, it is confirmed that a platform based product benefit from lower costs, although higher margins. However, group two and four reacted differently. In this case, the high quantity of products required for a single order reflected in lower costs of production (due to the economy of scale), as well as in lower margins (due to discount applied to customers in selling the product). However, the analysis has statistically confirmed the difference in the four clusters for the assembling, testing and overhead costs, with a p-value less than 0.05 . This may be due to the weight of the first clusters in relation to the others.

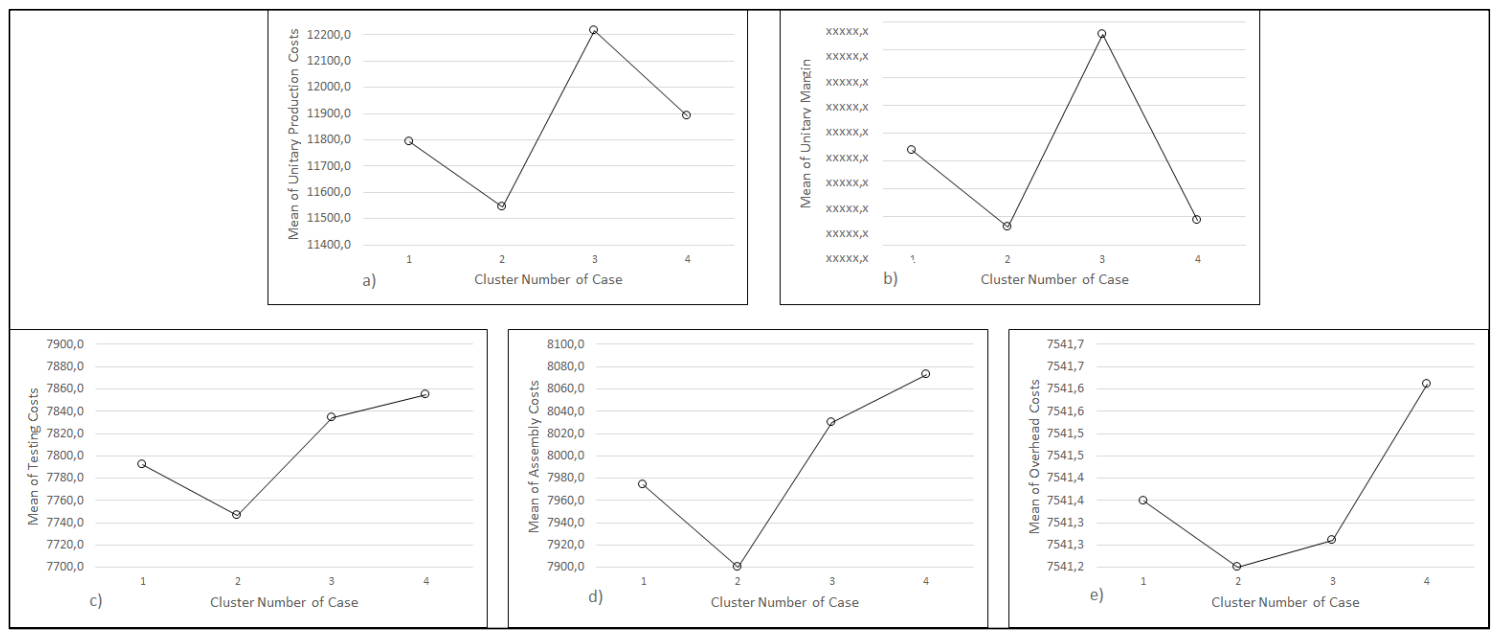

Figure 8. Cluster differences on the a) total production cost, b) margin, c) the testing cost, $d)$ the assembling cost, e) the overhead costs 
By this analysis implemented in the company, decisions in reducing the variety have been taken. In particular, ten different hardware options, designed mainly for a specific customer requirement, have been stopped.

\section{Conclusions}

Although the multitude of applications and methods for product cost estimation in the literature, their limited adoption in the industry has been observed. From a methodological perspective, the reasons are related to confusion on the approaches available, and ambiguity in their applications. From an implementation perspective, the main challenges are for companies in the process of data gathering, analysis and efficient utilisation. In fact, how to enable designers and managers to efficiently understand the strategic, operational consequences of a cost analysis implementation remains a problem, although advanced methodologies for more in-depth and timely analyses are available.

Hence, the paper addresses all these aspects, providing an approach for assessing a rigorous implementation of cost estimation methodologies, discussing the evidence derived from its operational and strategic impacts. In particular, a lifecycle cost methodology, previously introduced in Altavilla and Montagna (2015), has been employed. The novelty of this method is in the way the information has been employed, moving the investigation based on data aggregation level and the product structure. In this way, different cost estimation techniques have been used, namely the Case-Based Reasoning, the Activity Based Costing and the Parametric method.

The information framework derived at the end of the cost estimation process was then employed to assess the impact of a platform design strategy and variety proliferations on the total lifecycle costs. Empirically, a cluster analysis was used to identify similar product architecture based on their level of customisation. Successively, we assess the differences in lifecycle costs between the different groups of product configuration.

The approach was tested and validated in an industrial case. We evaluated the possible mix of options on a data acquisition device family, characterised by three product lines (for low, medium and high-end market segments) and a platform of 150 possible product variants. Hence, we provided empirical evidence on the optimal degree of variety for the product family, confirming the model validity. In fact, the model performs in line with the expected results discussed in the managerial literature.

In the end, we provided designers with a decision/making support that can help in making decisions for the planning activities of a new product family. In fact, designers through the steps proposed in the lifecycle methodology, are guided in the process of cost analysis. Moreover, the empirical evidence obtained in this paper, constitute a validation of the methodology that can easily adaptable at different cases of products and industry. Once the data framework is obtained, different other strategic analysis can be hence performed. In the specific occasion of the selected industrial case, we employed a detailed operational analysis (as the cost estimation) to inform and drive the strategic planning of product portfolio planning.

\section{References}

Altavilla, S. and Montagna, F. (2015), "When Costs From Being A Constraint Become A Driver For Concept Generation", Proceedings of the 20th International Conference on Engineering Design (ICED 15), Vol. 5: Design Methods and Tools-Part 1, Milan, Italy, July 27-30, 2015, The Design Society, Glasgow, pp. 125-134.

Altavilla, S., Montagna, F. and Cantamessa, M. (2018), "A multilayer taxonomy of Cost Estimation techniques, looking at the whole product lifecycle”, Journal of Manufacturing Science and Engineering, Vol. 140 No. 3, pp. 030801. https://doi.org/10.1115/1.4037763

Asiedu, Y. and Gu, P. (1998), "Product life cycle cost analysis: state of the art review", International Journal of Production Research, Vol. 36 No. 4, pp. 883-908. https://doi.org/10.1080/002075498193444

Brunoe, T.D. and Nielsen, P. (2012), "A case of cost estimation in an engineer-to-order company moving towards mass customization", International Journal of Mass Customisation, Vol. 4 No. 3-4, pp. 239-254. https://doi.org/10.1504/IJMASSC.2012.047400

Cavalieri, S., Maccarrone, P. and Pinto, R. (2004), "Parametric Vs Neural Network Models for the Estimation of Production Costs: A Case Study in the Automotive Industry", International Journal of Production Economics, Vol. 91 No. 2, pp. 165-177. https://doi.org/10.1016/j.ijpe.2003.08.005

Cheung, W.M., Marsh, R., Griffin, P.W., Newnes, L.B., Mileham, A.R. and Lanham, J.D. (2015), "Towards cleaner production: a roadmap for predicting product end-of-life costs at early design concept", Journal of Cleaner Production, Vol. 87, pp. 431-441. https://doi.org/10.1016/j.jclepro.2014.10.033 
Choudhary, A.K., Harding, J.A. and Tiwari, M.K. (2009), "Data mining in manufacturing: a review based on the kind of knowledge", Journal of Intelligent Manufacturing, Vol. 20 No. 5, pp. 501-521. https://doi.org/10.1007/s10845-008-0145-x

Deng, S. and Yeh, T.H. (2011), "Using least squares support vector machines for the airframe structures manufacturing cost estimation", International Journal of Production Economics, Vol. 131 No. 2, pp. 701-708. https://doi.org/10.1016/j.ijpe.2011.02.019

Dowlatshahi, S. (1992), "Product design in a concurrent engineering environment: an optimization approach", International Journal of Production Research, Vol. 30 No. 8, pp. 1803-1818. https://doi.org/10.1080/00207549208948123

Duran, O., Rodriguez, N. and Consalter, L.A. (2009), "Neural networks for cost estimation of shell and tube heat exchangers", Expert Systems with Applications, Vol. 36 No. 4, pp. 7435-7440. https://doi.org/10.1016/j.eswa.2008.09.014

Fazlollahtabar, H. and Mahdavi-Amiri, N. (2013), "Design of a neuro-fuzzy-regression expert system to estimate cost in a flexible jobshop automated manufacturing system", The International Journal of Advanced Manufacturing Technology, Vol. 67 No. 5-8, pp. 1809-1823. https://doi.org/10.1007/s00170-012-4610-5

Foster, G. and Gupta, M. (1990), "Manufacturing overhead cost driver analysis", Journal of Accounting and Economics, Vol. 12 No. 1-3, pp. 309-337. https://doi.org/10.1016/0165-4101(90)90052-6

Haroun, A.E. (2015), "Maintenance cost estimation: application of activity-based costing as a fair estimate method", Journal of Quality in Maintenance Engineering, Vol. 21 No. 3, pp. 258-270. https://doi.org/10.1108/JQME-04-2015-0015

Helbig, T., Hoos, J. and Westkämper, E. (2014), “A Method for Estimating and Evaluating Life Cycle Costs of Decentralized Component-based Automation Solutions", Procedia CIRP, Vol. 17, pp. 332-337. https://doi.org/10.1016/j.procir.2014.01.117

Hicks, B.J., Culley, S.J., Allen, R.D. and Mullineux, G. (2002), “A framework for the requirements of capturing, storing and reusing information and knowledge in engineering design", International Journal of Information Management, Vol. 22 No. 4, pp. 263-280. https://doi.org/10.1016/S0268-4012(02)00012-9

H'mida, F., Martin, P. and Vernadat, F. (2006), "Cost estimation in mechanical production: The Cost Entity approach applied to integrated product engineering", International journal of production economics, Vol. 103 No. 1, pp. 17-35. https://doi.org/10.1016/j.ijpe.2005.02.016

Holzhauser, K. and Schalla, P. (2017), "Digital Transformation in Manufacturing”, In: Ellermann, H., Kreutter, P. and Messner, W. (Eds.), The Palgrave Handbook of Managing Continuous Business Transformation, Palgrave Macmillan, UK, pp. 273-288. https://doi.org/10.1057/978-1-137-60228-2_12

Hongzhuan, C., Kaifeng, F. and Zhigeng, F. (2013), "Research on complex product cost estimation based on the N-GM (0, N) model”, Grey Systems: Theory and Application, Vol. 3 No. 1, pp. 46-59. https://doi.org/10.1108/20439371311293697

Johnson, M.D. and Kirchain, R.E. (2009), "Quantifying the effects of product family decisions on material selection: A process-based costing approach”, International Journal of Production Economics, Vol. 120 No. 2, pp. 653-668. https://doi.org/10.1016/j.ijpe.2009.04.014

Kaufmann, M., Zenkert, D. and Mattei, C. (2008), "Cost optimization of composite aircraft structures including variable laminate qualities", Composites Science and Technology, Vol. 68 No. 13, pp. 2748-2755. https://doi.org/10.1016/j.compscitech.2008.05.024

Kekre, S. and Srinivasan, K. (1990), “Broader Product Line: A Necessity to Achieve Success?", Management Science, Vol. 36 No. 10, pp. 1216-1231. https://doi.org/10.1287/mnsc.36.10.1216

Krishnan, V. and Gupta, S. (2001), "Appropriateness and impact of platform-based product development", Management Science, Vol. 47 No. 1, pp. 52-68. https://doi.org/10.1287/mnsc.47.1.52.10665

Krishnan, V., Singh, R. and Tirupati, D. (1999), "A model-based approach for planning and developing a family of technology-based products", Manufacturing \& Service Operations Management, Vol. 1 No. 2, pp. 132-156. https://doi.org/10.1287/msom.1.2.132

Layer, A., Brinke, E.T., Houten, F.V., Kals, H. and Haasis, S. (2002), "Recent and future trends in cost estimation", International Journal of Computer Integrated Manufacturing, Vol. 15 No. 6, pp. 499-510. https://doi.org/10.1080/09511920210143372

Lee, H.C., Lee, J.M. and Seo, J.H. (2011), "Design and improvement of product using intelligent function model based cost estimating", Expert systems with applications, Vol. 38 No. 4, pp. 3131-3141. https://doi.org/10.1016/j.eswa.2010.08.105

Lin, T., Lee, J.W. and Lwin, T. (2011), "Integrated approach for rotor blade manufacturing cost estimate", Aircraft Engineering and Aerospace Technology, Vol. 83 No. 4, pp. 235-244. https://doi.org/10.1108/00022661111138657 
Lindholm, A. and Suomala, P. (2007), "Learning by costing: Sharpening cost image through life cycle costing?", International journal of productivity and performance management, Vol. 56 No. 8, pp. 651-672. https://doi.org/10.1108/17410400710832985

Liu, H., Gopalkrishnan, V., Ng, W.K., Song, B. and Li, X. (2008), “An intelligent system for estimating full product Life Cycle Cost at the early design stage", International Journal of Product Lifecycle Management, Vol. 3 No. 2-3, pp. 96-113. https://doi.org/10.1504/IJPLM.2008.021436

Loyer, J.L. and Henriques, E. (2014), “A MBSE probabilistic framework for preliminary lifecycle costing of mechanical products”, INCOSE International Symposium, Vol. 24 No. 1, pp. 182-195. https://doi.org/10.1002/j.2334-5837.2014.tb03143.x

Ma, Y-S., Sajadfar, N. and Campos, L. (2014), "A feature-based semantic model for automatic product cost estimation", International Journal of Engineering and Technology, Vol. 6 No. 2, pp. 109-113. https://doi.org/10.7763/IJET.2014.V6.676

Meyer, M.H. and Utterback, J.M. (1993), "The product family and the dynamics of core capability", Sloan management review, Vol. 34 No. 3, pp. 29-47.

Newnes, L.B., Mileham, A.R., Cheung, W.M., Marsh, R., Lanham, J.D. et al. (2008), "Predicting the whole-life cost of a product at the conceptual design stage", Journal of Engineering Design, Vol. 19 No. 2, pp. 99-112. https://doi.org/10.1080/09544820701803061

Niazi, A., Dai, J.S., Balabani, S. and Seneviratne, L. (2006), "Product cost estimation: Technique classification and methodology review", Journal of manufacturing science and engineering, Vol. 128 No. 2, pp. 563-575. https://doi.org/10.1115/1.2137750

Park, J. and Simpson, T.W. (2008), "Toward an activity-based costing system for product families and product platforms in the early stages of development", International Journal of Production Research, Vol. 46 No. 1, pp. 99-130. https://doi.org/10.1080/00207540600825240

Rush, C. and Roy, R. (2000), "Analysis of cost estimating processes used within a concurrent engineering environment throughout a product life cycle", Proceedings of the 7th ISPE International Conference on Concurrent Engineering: Research and Applications (CE2000), Lyon, France, July 17-20, 2000, Technomic Inc, Lancaster, USA, pp. 58-67.

Sajadfar, N. and Ma, Y. (2015), "A hybrid cost estimation framework based on feature-oriented data mining approach", Advanced Engineering Informatics, Vol. 29 No. 3, pp. 633-647. https://doi.org/10.1016/j.aei.2015.06.001

Saravi, M., Newnes, L., Mileham, A.R. and Goh, Y.M. (2008), "Estimating cost at the conceptual design stage to optimize design in terms of performance and cost", Proceedings of the 15th ISPE International Conference on Concurrent Engineering (CE2008), Belfast, Northern Ireland, UK, August 18-22, 2008, Springer London, pp. 123-130. https://doi.org/10.1007/978-1-84800-972-1_11

Seo, K.K. (2006), "A methodology for estimating the product life cycle cost using a hybrid GA and ANN model”, Proceedings of 16th International Conference on Artificial Neural Networks, Athens, Greece, September 1014, 2006, Springer Berlin Heidelberg, pp. 386-395. https://doi.org/10.1007/11840817_41

Seo, K.K. and Ahn, B.J. (2006), "A learning algorithm based estimation method for maintenance cost of product concepts”, Computers \& Industrial Engineering, Vol. $50 \quad$ No. 1 , pp. 66-75. https://doi.org/10.1016/j.cie.2005.12.003

Simpson, T.W. (2004), "Product platform design and customization: Status and promise", Artificial Intelligence for Engineering Design, Analysis and Manufacturing, Vol. 18 No. 1, pp. 3-20. https://doi.org/10.1017/S0890060404040028

Waghmode, L.Y. (2014), "A suggested framework for product life cycle cost analysis at product design stage", International Journal of Sustainable Design, Vol. 2 No. 3, pp. 244-264. https://doi.org/10.1504/IJSDES.2014.065042

Yadav, R. and Sharma, A. (2016), "A research review on approaches/techniques used in big data environment", Proceedings of the Fourth International Conference on Parallel, Distributed and Grid Computing (PDGC), Waknaghat, India, December 22-24, 2016, IEEE, pp. 242-252. https://doi.org/10.1109/PDGC.2016.7913153

Zhao, X., Verhagen, W.J. and Curran, R. (2015), "Estimation of aircraft component production cost using knowledge based engineering techniques", Advanced Engineering Informatics, Vol. 29 No. 3, pp. 616-632. https://doi.org/10.1016/j.aei.2015.05.004

Stefania Altavilla, $\mathrm{PhD}$ student

Politecnico di Torino, Management and Production Engineering

Via Giacomo Leopardi 16, 72029 Villa castelli, Italy

Email: stefania.altavilla@polito.it 